\title{
PROGRESSO E FUTURO DO DIREITO INTERNACIONAL
}

\section{O CONGRESSO DE VIENNA}

O Congresso de Vienna, teve, como principal missão, reconstruir a Europa. Sua influencia reaccionaria foi enorme, contribuiu comtudo para o progresso do D. $I$. com algumas regras: - regulamentação da navegação fluvial, declaração contra o tráfico de negros, hierarchia dos agentes diplomaticos.

A politica reaccionaria do Congresso de Vienna, tendo como fundamento o famigerado principio da legitimidade tem como consequencia várias intervenções, objecto dos Congressos de Aix-la-Chapelle, Troppau, Laybach e Verona.

CONGRESSO DE PARIZ DE 1856.

Esse congresso marca uma época importantissima na historia do D. I. Por elle a Turquia entra para a familia das Nações. A decl. de 16 de Abril de 1856 sobre o Direito Maritimo é de uma importancia capital. Por ella:

1. ${ }^{\circ}$ Fica abolido o corso.

$2 .^{\circ}$ O pavililhão neutro cobre-a mercadoria inimig:। com excepção do contrabando de guerra.

3. Não é confiscavel a mercadoria neutra sob a balldeira inimiga (Lafayette, 2 p. 341, § 460) 
$4 .^{\circ}$ Os bloqueios só são obrigatorios quando effectivos, i. é, mantidos por forças sufficientes.

Graças a este tratado a garantia e a mediação fazem progressos, começando então a er das convenções.,

\section{AS CONFERENCIAS DE HAYA}

Após numerosos congressos, realizaram-se as conferencias de Haya. Como ensina Nippold, quando o convite do $C z a r$ foi publicado nos jornaes, comę̧ou lógo uma campanha surda contra a óbra generosa de Haya. Estavam em jogo varios interesses: do capitalismo, do militarismo E' verdade que como conferencia de desarmamentos houve fracasso, mas é necessario convir que a sua influencia internacional foi enorme. Alem dos bons officios e da mediação, processos internacionaes por ella organizados, das commissões d'inquerito e do arbitramento, codificou a 1. ${ }^{a}$ Conferencia as leis da guerra. Mas a óbra de Haya tem um aspecto que sobreleva todos os outros: - fazer com que os povos tivessem consciencia nitida da solidariedade internaconal.

\section{A LIGA DAS NAÇÕES}

A idea de uma organização internacional é antiquissima. Já na Hellade encontramos 'as Amphiationias e atravez dos seculos os maiores pensadores occuparam-se com o assumpto apresentandio planos de paz perpétua. Pierre Dubois, Podiebrad, Campanella, Eméric Crucé, Sully, o Abbade de St. Pierre, Bentham, 'Wolff, Kant, são nomes que trazem ao espirito a idéa de planos célebres de organização internàcional.

Vemos pois juristas e philosophos darem-se as mãos e trabalharem solidariamente para a paz internacional. Esses projectos foram considerados utopistas, comtudo contribuiram grandemente para o progresso do D. I. 


\section{$-203-$ \\ SÖCIEDADES PARA A PAZ}

No sec. IX, ao lado de numerosos planos de organização internacional, surgem sociedades para a paz. A 1. fundou-se em 1815 na America.

O movimento pacifista augmenta. Em 1915, formase em Londres, por iniciativa de Bryce a "Leagu of $\mathrm{Na}$ tions Society. Em 1918 forma-se uma rival "The League of Free Nations Association" Unem-se depois as duas, e formam "The League of Nations Union"

Um movimento analogo dá-se na America onde (1916) funda-se a "League to enforce Peace"

\section{WILSON}

Mas, apesar de todos os esforços, a Liga da Nações deve sua existencia a Wilson. Feita a paz, no trat. de Versailles a parte I é o Pacto da Liga das Nações.

\section{CARACTER DA LIGA}

Como ensina Oppenheim (I p. 268), a liga não é uma Confederação niem: uma mera Alliança.

E' uma organização sui-generis, que tenta substituir a Famila das Nações, e o Pacto nada mais é do que uma tentativa para organizar a antiga communhão dos estados por meio de uma constituição escripta.

A Liga das Nações é uma pessoa sui-generis de Direito Internacional. Si algum dia for dissolvida, sendo apenas a organização da Familita das Nações, esta voltará á sua primitiva condição.

\section{FINS}

Dois são os fins da Liga - Manter a paz e promover a cooperação internacional. 


\section{A LIGA DAS NAÇÕES E A SOBERANI'A NACIONAL}

Dizem que a liga attaca a soberania naconal. E' uma objecção falsa. A soberania é divisivel e limitada e porisso não ha nada de absurdo em limitar o Liga a soberania dos estados.

\section{A LIGA E A NOSSA CONSTITUIÇÃO}

Ao subscrever o Brasil o tratado de Paz violou 2 artigos da Const. Federal: -88 e 34 n. ${ }^{\circ} 17$.

Mas ninguem se preoccupou nunca no Brasil com a Constituição federal. E' esse o motivo porque nas minhas aulas de D. Constitucional affirmei que era inutil tentar reformar a nossa Constituição: - tanto nos vale uma como outra, como nenhuma

Enumerarei algumas.

\section{Violações da Constituição:}

Questões de limites entre Estados; que os Estados vivam á sua custa; autonomia estadoal; impostos inter-esta. doaes e inter-municipaes; organização da força armada pelo Congresso; prohibição de delegação de attribuições legislativas ao Executivo; immunidade parlamentar, sem restricções; prohibição do exercicio simultaneo de senador e deputado, data certa para a reunião do Congresso; preenchimento immediato das vagas de congressistas; Isenção de impostos para o subsidio; prohibição de que os congressistas façam parte de emprezas que recebem favores do Governo; representaçção das minorias; proporção entre os deputados e a popuação verificada; prohibição de delegaçã̃o ao Executivo para suppressão de empregos; prestação de contas pelo Executivo ao Legislativo; andamento rapido dos vetos; renovação, na mesma sessão legislativa, de medidas rejeitadas; alteração no sub- 
sidio do Presidente e do Vice-Presidente da Republica; o deputado é escolhidio ministro a a vaga fica aberta .; ausencia de relatorios de ministros; responsabilidade do Presidente dia Republica pelo não cumprimento de disposições das leis orçamentarias; diminuição de vencimentos dos magistrados; prohibição da reeleição dos governadores (implicitamente); propriedade de minas; entrega aos Estados das propriedades de que a União não necessite; represalias entre Estados: intervenção em orçamentos locaes; alistamento releitoral; gratuidade do casamento; subvenção a cultos; livre transito em todo o territorio nacional; inviolabilidade de domicilio; liberdade de reunião e de tribuna; nota de culpa para a prisão; sigillo da correspondencia; prévia indemnização de qualquer desapropriação; impostos não emanados do Legislativo; responsabilidade dos funccionarios publicos; obrigatoriedade do serviço mlitar; prohibição do recrutamento forçado; recenséamento decennal: organização do Tribunal de Contas como orgão do Legislativo e não do Executivo.

Tinhamos portanto, si quizessemos entrar juridicamente na liga que reformar a nossa Constituição.

Existe como ensina Triepel o direito interno internacionalmente importante e o direito interno que é internacionalmente indilfferente. $\mathrm{O}$ primeiro, pode ser conforme ou contrario ao D, Internacional. O conforme ao D. I., é direito interno ordenado ou simplesmente autorizado por elle. Seria no caso necessario que o Brasil creasse um direito interno de accordo com o Pacto da Liga (dircito interno internacionalmente indispensavel).

\section{OUTRAS OBJECÇÕES}

Fazem-se varias outras objecções contra a Liga (oppenheim, I p. 291), 'mas ellas se applicariam em geral á Familia das Nações de que a liga é a organizaçção. 


\section{CONCLUSÃO}

Para existir uma sociedade de Nações seria necessario a sua universalidade e democratização.

\section{FUTURO DO DIREITO INTERNACIONAL}

Em que pese á opinião de Nippold, não temos ainda no mundo a verdadeira democracia. Esta é incompativel com a guerra. Para conseguirmos a paz no mundo precisamos educar o povo, preparando-o para comprehender e amar á solidariedade internacional, e iṣso só conseguiremos com a democracia.

\section{PASSOS PARA A FRENTE}

No Uruguay já existe o ensino da moral internacional nos cursos primario e secundiario.

Outra instituição que muito contribuirá para o progresso do Direito Internacional é a

Academia de Direito Internacionãl de Haya

Esta Academia, onde leccionam homens da estatura de Nippold, Dupuis, Pillet, Mahaim, Gemma, Diena, Planas Suarez, Weiss Alvarez, tem encontrado appoio official por parte de numerosos estados, como a Allemanha, a Bulgaria, a China, a Dinamarca, o Siam e a Turquia. Convidado a escolher dois estudantes para, em nome do Brasil, representarem a nossa Faculdade, cursando as aulas da notavel Academia de D. Internacional, escolhi os Snrs. João Pereira Monteiro e Dante Delmanto. Acceita a minha indicação, foram elles para Haya, onde cursaram as aulas.

Infelizmente, o nosso Governo e a nossa Faculdade não compehendendo o alcance de tão importante commis- 
são internacional, com desculpas improcedentes, excursaram-se de auxiliar condignamente esses rapazes.

$\mathrm{O}$ facto foi por mim denunciado am artigo com o titulo intercambio academico. Ficamos abaixo do Siam e da China!

\section{TRIUMPHO DA DEMOCRACIA}

Só com a educação moral dos póvos e o triumpho da democracia, hão de acabar-se as guerras.

\section{O EXEMPLO DINAMARQUEZ}

Por iniciativa do Ministerio socialista Stauning a Dinamarca desarma-se completamente. Apesar das advertencias dos francezes nadia lhe acontece

Bello exemplo ao mundo!

\section{FUTUURO}

Não devemos temer o futuro: - o sentimenio da solidariedade entre os póvos augmenta dia a dia.

0 povo é todo contra a guerra, e esta vae se tornando impossivel. Um enormel sopro de progresso agita o mundo.

As cantigas sediças dos oligarchas e escravizadores dos póvos, já não produzem effeito.

O. reino d'a Democracia está proximo, e com ella não será mais possivel a guerra.

Encaremos o futuro com confiança e preparemo-n s para o dia de amanhã.

S. Paulo, abril de 1927

Braz de Sousa Arruda 